\title{
Roles of gall bladder emptying and intestinal transit in the pathogenesis of octreotide induced gall bladder stones
}

\author{
S H Hussaini, S P Pereira, M J Veysey, C Kennedy, P Jenkins, G M Murphy, J A H Wass, \\ R H Dowling
}

\begin{abstract}
Background-Octreotide treatment of acromegalic patients increases the \% deoxycholic acid conjugates and the cholesterol saturation of gall bladder bile, and induces gall stone formation.

Aims-To study the roles of gall bladder emptying and intestinal transit in these phenomena.

Methods and patients-Gall bladder emptying and mouth to caecum transit was measured in (a) control subjects and acromegalic patients given saline or $50 \mu \mathrm{g}$ of octreotide, and (b) acromegalic patients taking long term octreotide. In the second group, large bowel transit was also measured.
\end{abstract}

Results-A single dose of octreotide inhibited meal stimulated gall bladder emptying, the ejection fraction falling from mean (SEM) $66.0(2 \cdot 3) \%$ to $7 \cdot 0$ $(5 \cdot 3) \%$ in controls $(p<0.001)$; from 72.5 $(2 \cdot 1)$ to $16 \cdot 6(5 \cdot 1) \%$ in untreated acromegalic patients $(\mathbf{p}<0.001)$, and to 30.4 (9.5) $\%$ in acromegalic patients taking long term octreotide $(p<0 \cdot 001 v$ untreated acromegalic group). Octreotide prolonged mouth to caecum transit time, from 112 (15) $\mathrm{min}$ to 237 (13) $\mathrm{min}$ in controls $(p<0 \cdot 001)$, from 170 (13) $\mathrm{min}$ to 282 (11) $\mathrm{min}$ in untreated acromegalic patients $(p<0 \cdot 001)$, and to $247(10) \mathrm{min}$ in acromegalic patients taking long term octreotide $(p<0.001 v$ untreated acromegalic patients). The mean large bowel transit in octreotide untreated compared with treated acromegalic patients remained unchanged (40 (6) h $v 47(6) \mathrm{h}$ ). Conclusions-Prolongation of intestinal transit and impaired gall bladder emptying may contribute to lithogenic changes in bile composition and gall stone formation in patients receiving long term octreotide. (Gut 1996; 38: 775-783)

Keywords: deoxycholic acid, gall bladder emptying, octreotide, mouth to caecum transit time, large bowel transit time, gall bladder stones.

Octreotide, a long acting analogue of somatostatin, suppresses circulating growth hormone and insulin-like growth factor (IGF-1) concentrations, and is an effective treatment for acromegaly. However, after 12 months' treatment octreotide induces gall bladder stones in up to $50 \%$ of patients. ${ }^{12}$
'Conventional' cholesterol gall stones, unrelated to acromegaly or octreotide treatment, develop when at least three abnormalities coexist - the so called triple defect ${ }^{3}$ : (a) supersaturation of gall bladder bile with cholesterol, (b) rapid nucleation of cholesterol microcrystals, and (c) retention of these crystals within the gall bladder - in part because of gall bladder motor dysfunction. Octreotide treatment impairs gall bladder emptying ${ }^{4-6}$ mainly, but not solely, as a result of inhibiting meal stimulated cholecystokinin release from the intestine. ${ }^{6-8}$ Until recently, the resultant stasis of bile within the gall bladder was considered to be the principal mechanism whereby octreotide induced gall bladder stones. ${ }^{2}$ However, we showed ${ }^{9}$ that long term (>3 months) octreotide treatment induces lithogenic changes in gall bladder bile - namely supersaturation with cholesterol and an increase in the proportion of deoxycholic acid (DCA) conjugates.

There are several possible mechanisms whereby octreotide treatment might increase the $\%$ of deoxycholic conjugates in bile. Firstly, it could lead to prolongation of intestinal transit, the resultant increase in residence time of bile acids in the intestine favouring bacterial $7 \alpha$ dehydroxylation of cholic acid to deoxycholic acid. ${ }^{10-12}$ Secondly, the impaired gall bladder emptying might increase the proportion of DCA conjugates in bile as a result of loss of the gall bladder's reservoir function, increased enterohepatic cycling of the displaced bile acids, and thus repeated exposure of the circulating cholate pool to intestinal bacterial $7 \alpha$ dehydroxylation ${ }^{13}$ - analogous to that described by some, ${ }^{14}$ but not all, ${ }^{15}$ investigators after cholecystectomy.

To date, the effects of octreotide on intestinal transit and gall bladder emptying have been studied mostly in control subjects given a single dose of the somatostatin analogue. ${ }^{7} 16$ There have been only a few studies of the effects of long term octreotide on gall bladder emptying, ${ }^{417}$ and none on small bowel transit in acromegalic patients. Furthermore, with one exception, ${ }^{18}$ there have been no studies of the effects of octreotide on large bowel transit.

In this report, we describe the effects of short-term and long term octreotide treatment on meal stimulated gall bladder emptying and small bowel transit (mouth to caecum transit time: MCTT), and of long term octreotide on large bowel transit time (LBTT), in both control subjects and acromegalic patients. 


\section{Methods}

\section{STUDY DESIGN}

The study was designed in two parts. The first examined the short-term effects of octreotide in control subjects and acromegalic patients. The second examined the effects of long term octreotide in acromegalic patients. Although the groups of acromegalic patients studied in each part were similar, five of 11 patients were common to both parts.

\section{GP.LL BLADDER EMPTYING MCTT}

\section{Protocol}

A subcutaneous injection of either placebo (saline) or octreotide $(50 \mu \mathrm{g})$ was given 30 minutes before the subjects drank a fat-rich liquid test meal ( $250 \mathrm{ml}$ 'Ensure') together with $20 \mathrm{ml}$ of lactulose (a substrate for breath hydrogen). Thereafter, gall bladder emptying was assessed from ultrasound measurements of gall bladder volume, ${ }^{19}$ and MCTT was measured by the breath hydrogen technique. 2021

For the paired studies, a randomised, double blind, placebo controlled, cross over design was used for both the control subjects and the acromegalic patients. The study was then repeated one to three weeks later with the alternative injection - saline or octreotide as appropriate. In the long term study, acromegalic patients treated with octreotide for more than three months were examined on a single occasion. As in the paired studies, the octreotide was injected 30 minutes before the meal stimulus.

\section{PATIENTS}

\section{Paired studies}

Ten control subjects (mean (SEM) age 30 (1.7); range 23-40 years) were studied, five of whom were men. The subjects had a mean body mass index of $24.7 \quad(1.0)$ (range 18.2-29.4). Twelve acromegalic patients (mean age $46(4.9)$; range $21-67$ ) were studied, six of whom were men. The mean body mass index in the 12 patients was $29.8(1.5)$

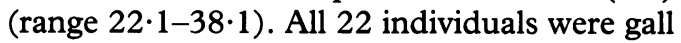
stone free by ultrasound and none of the acromegalic patients had been treated previously with octreotide. One subject from the control, and one from the acromegalic, groups did not attend for a second study.

\section{Long term studies}

Ten acromegalic patients (mean age 46 (5.3); range 22-69 years) were studied, four of whom were men. The mean body mass index in these patients was $29 \cdot 3(1 \cdot 8)$ (range 19.6-38.1). They had been treated with 300-600 $\mu \mathrm{g}$ octreotide/day for three to 48 (median 6) months. These 10 patients were all gall stone free by ultrasound before octreotide treatment began, but at the time of the long term studies two had developed gall bladder stones.

\section{GALL BLADDER EMPTYING}

This was assessed from ultrasound measurements of gall bladder volume, using the ellipsoid method. ${ }^{19}$ The volume measurements were taken at 30 minutes and immediately before the test meal, and every 15 minutes thereafter - either until the gall bladder volume had returned to its pre-meal value, or for a maximum of 90 minutes after the meal. All measurements were made in triplicate. Two experienced ultrasonographers carried out the measurements although, for any one paired study, the same operator was used.

The following parameters of gall bladder emptying were calculated: (a) fasting volume (FV) - that is, the gall bladder volume immediately before ingesting the test meal, (b) residual volume ( $R V$ ) - the nadir gall bladder volume recorded after the test meal, (c) delta volume (DV) or the change in gall bladder volume (fasting minus residual volume), (d) ejection 'fraction' - that is, the DV expressed as a percentage of fasting volume, and (e) rate of gall bladder emptying - the DV divided by the time taken to reach the RV - expressed in $\mathrm{ml} / \mathrm{min}$. All the volume measurements were in $\mathrm{ml}$.

\section{MCTT}

The MCTT was measured using the breath hydrogen technique. In brief, end expiratory breath samples were collected in a $20 \mathrm{ml}$ plastic syringe, 30 minutes and immediately before the test meal, and every 15 minutes thereafter. The samples were collected until either a late peak of breath hydrogen (a rise of $10 \mathrm{ppm}$ above baseline on two consecutive occasions) occurred, or 300 minutes after meal ingestion. Thereafter, the findings were abandoned - even in the absence of a demonstrable rise in breath hydrogen.

Breath samples were analysed immediately using a pre-calibrated, hydrogen sensitive electrochemical cell (Key Med), which measures hydrogen concentrations within 30 seconds, to an accuracy of $2 \mathrm{ppm}$.

LBTT

\section{Patients}

Three groups of patients were studied: (a) 19 control subjects ( 14 of whom were men; mean age $34(2.5)$; range 23-57 years), (b) 12 acromegalic patients untreated with octreotide (six men; mean age 50 (4.7); range 21-69), and (c) nine acromegalic patients (four men; mean age $46(5 \cdot 3)$; range $22-69)$ treated with octreotide in a dose of $300-600 \mu \mathrm{g} /$ day for three to 48 months (median nine months).

\section{Methods}

LBTT was assessed by recording the progress of radio-opaque marker shapes through the colon. ${ }^{22}$ In brief, on three successive mornings at $900 \mathrm{am}$, the subjects and patients ingested 20, radiologically distinguishable, barium impregnated, polyvinylchoride marker shapes 


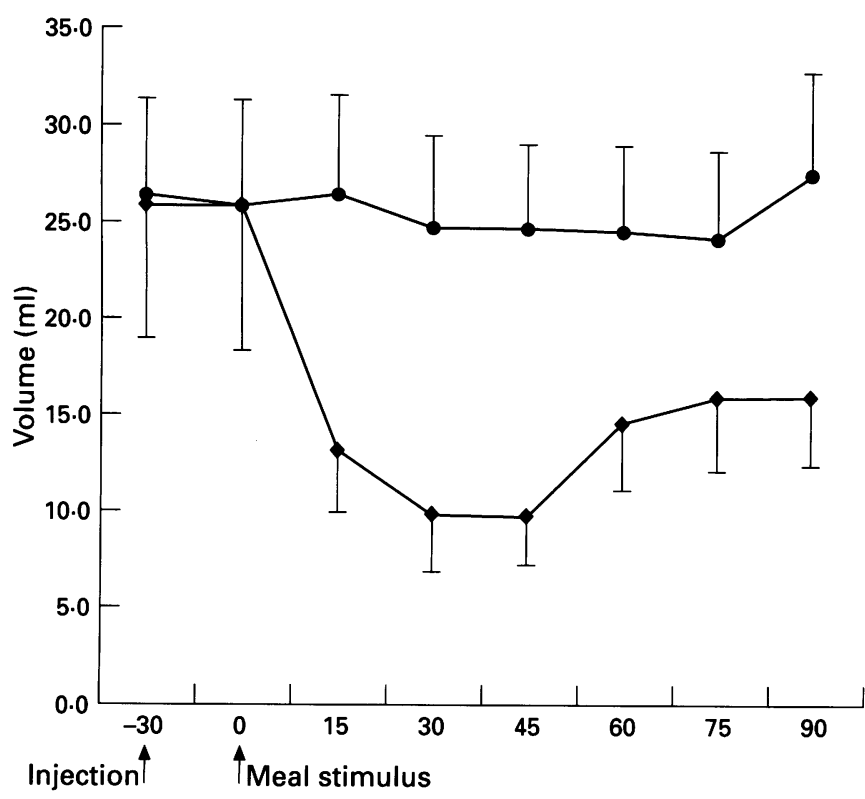

Single dose octreotide

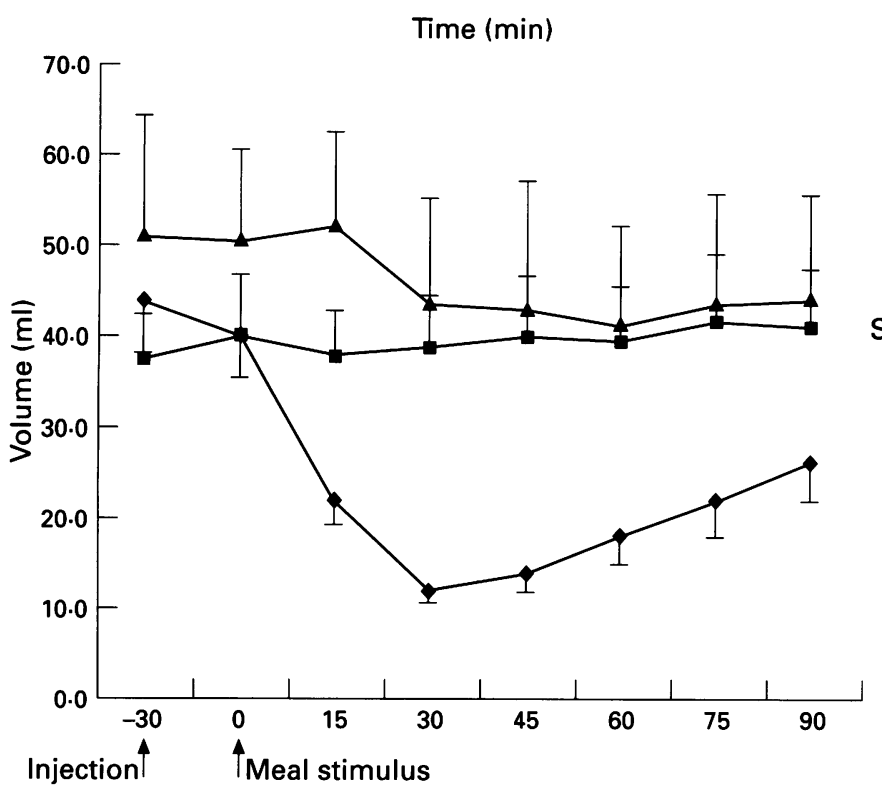

Time (min)

Figure 1: Effect of octreotide (50 $\mu \mathrm{g}$ ) or saline injections, given 30 minutes before food, on meal stimulated gall bladder emptying, as judged by serial measurements of gall bladder volume (mean (SEM)), in control subjects (upper panel) and acromegalic patients (lower panel). In the acromegalic patients, the effect of long term (>three months) octreotide treatment (300-600 $\mu \mathrm{g} /$ day given subcutaneously) is also shown. These patients also took their last dose of octreotide 30 minutes before the meal stimulus.

(small rings, large rings, and rods, with a maximum size of $6 \times 6 \mathrm{~mm}$ ), contained in a single gelatine capsule, with breakfast. They were asked to eat normally over the three day period and to maintain their normal pattern of defecation. A plain abdominal radiograph was taken on day four at approximately $900 \mathrm{am}$. The mean total colonic transit time, and the segmental right, left, and sigmoid colon transit times, were measured as described by Metcalf and colleagues. 22

\section{ETHICAL CONSIDERATIONS}

The study was approved by the research ethics committee of St Bartholomew's Hospital and by the ethics committee of Guy's Hospital. All patients gave their written informed consent.
STATISTICAL ANALYSES

The statistical significance of differences in results between the patient groups, and in the paired studies, was tested with the nonparametric hetroscedastic $t$ test using Excel software version 5.0 (Microsoft Corporation, 1 Microsoft Way, Redmond, WA 98052-6399). A $p$ value of $<0.05$ was considered to be statistically significant.

\section{Results}

GALL BLADDER EMPTYING

Figure 1 shows the results for the fasting and postprandial gall bladder volume/time profiles in control subjects (upper panel) and acromegalic patients (lower panel), given either saline or $50 \mu \mathrm{g}$ octreotide 30 minutes before the liquid test meal. The data for gall bladder emptying in acromegalic patients treated long term with octreotide are also shown in the lower panel of Fig 1.

The data for fasting, residual, and delta volumes, together with those for the ejection fractions and the rates of gall bladder emptying in control subjects and acromegalic patients after placebo, a single dose of octreotide or long term octreotide, are given in Fig 2 (A, B, and $\mathrm{C}$ ).

\section{Postprandial gall bladder emptying after a saline} (placebo) injection

In control subjects given saline, the mean (SEM) fasting volume of $25 \cdot 7(7 \cdot 3) \mathrm{ml}$ fell to a residual volume of $8 \cdot 7(2 \cdot 7) \mathrm{ml}, 30-75$ minutes (mean $41.7(6.0)$ ) after meal ingestion corresponding to a delta volume of $17 \cdot 0(5 \cdot 2)$ $\mathrm{ml}$, an ejection fraction of $66.0(2.3) \%$ and an emptying rate of $0.70(0.4) \mathrm{ml} / \mathrm{min}$.

In the acromegalic patients, the mean fasting gall bladder volume was greater than that in the control subjects, although the $56 \%$ difference between these groups was not statistically significant. The mean delta volume $(29.9$ (4.2) $\mathrm{ml}$ ) was also greater in the patient group than in the controls but again, this difference $(76 \%)$ was not statistically significant. There were only small differences between the two groups, however, in the residual volume $(19 \%)$, ejection fraction $(10 \%)$, and rate of gall bladder emptying $(24 \%)$ in response to the fatty meal and again these differences were not statistically different (Fig 2B).

\section{Postprandial gall bladder emptying after a single} octreotide injection

A single dose of octreotide essentially abolished meal stimulated gall bladder contraction in both control subjects and acromegalic patients (Fig 1).

In the control subjects given $50 \mu \mathrm{g}$ of octreotide, there were pronounced reductions in the ejection fraction (a 89\% change in the mean value compared with the results in the same subjects given saline; $p<0 \cdot 001)$, the delta volume $(84 \% ; p<0.02)$, and the rate of gall bladder emptying $(93 \%)$ although, given the 

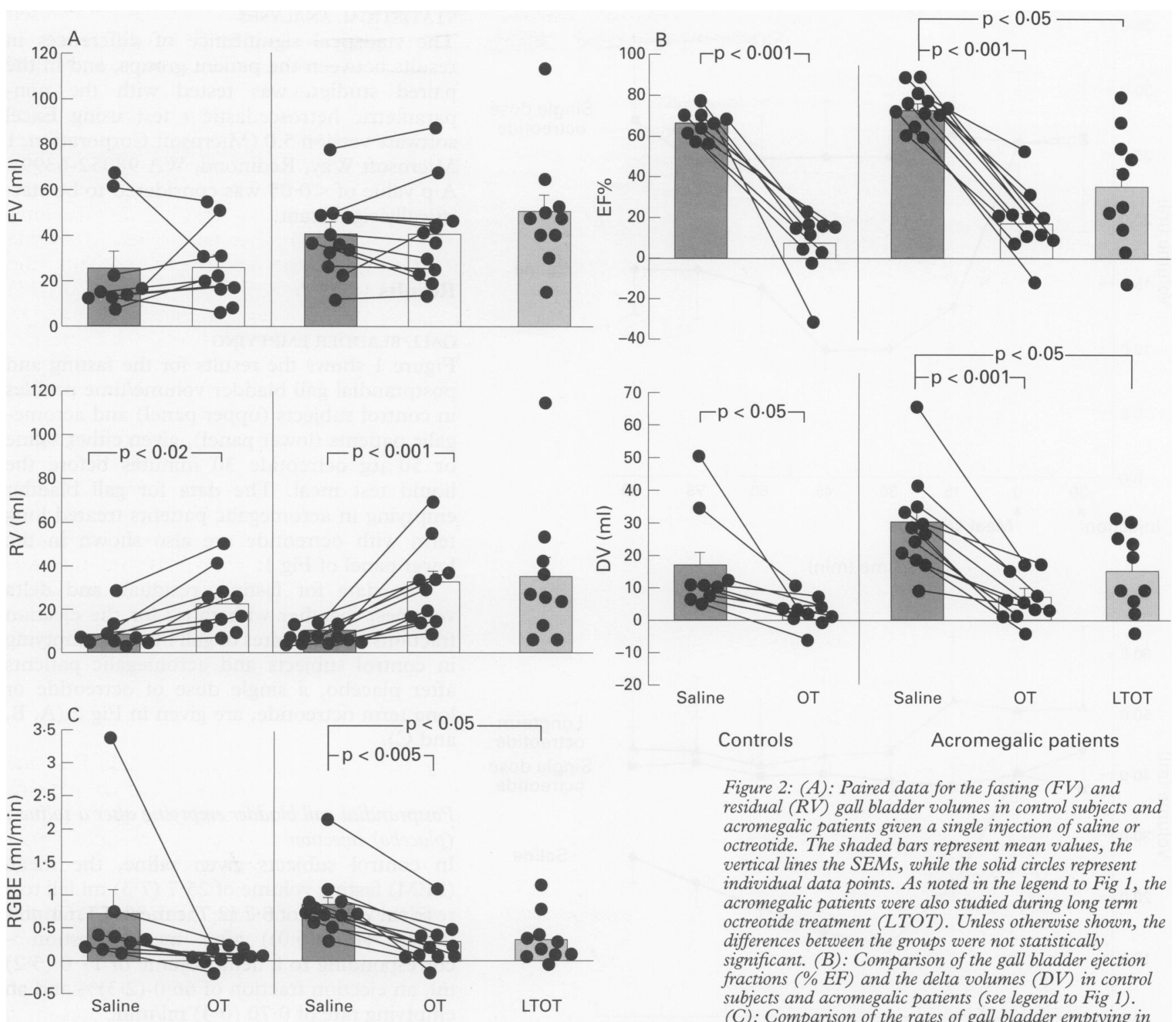

Controls

Acromegalic patients

Figure 2: (A): Paired data for the fasting (FV) and residual $(R V)$ gall bladder volumes in control subjects and acromegalic patients given a single injection of saline or octreotide. The shaded bars represent mean values, the vertical lines the SEMs, while the solid circles represent individual data points. As noted in the legend to Fig 1, the acromegalic patients were also studied during long term octreotide treatment (LTOT). Unless otherwise shown, the differences between the groups were not statistically significant. $(B)$ : Comparison of the gall bladder ejection fractions $(\% E F)$ and the delta volumes $(D V)$ in control subjects and acromegalic patients (see legend to Fig 1). (C): Comparison of the rates of gall bladder emptying in control subjects and acromegalic patients (see legend to Fig 1).

Controls Acromegalic patients

Postprandial gall bladder emptying after long term

scatter results, the difference for the rate of gall bladder emptying was not statistically significant. Moreover, the mean residual volume after octreotide was more than $250 \%$ greater than that seen after saline (Fig 2A; lower panel).

In the acromegalic patients, as in the controls, $50 \mu \mathrm{g}$ octreotide again led to significant falls in the delta volume (a $77 \%$ decrease compared with saline), the ejection fraction $(77 \%)$, and the rate of gall bladder emptying $(68 \%)$, and to a significant rise (over $200 \%$ ) in the residual volume when compared with the corresponding variables after saline (Figs 1 and 2).

The mean residual volume in the acromegalic patients given a single injection of octreotide $(33.2(5.4) \mathrm{ml})$ was greater than that of the control subjects given octreotide $(23.2(4 \cdot 3) \mathrm{ml}$; NS). Indeed, the mean values for delta volume, ejection fraction, and rate of gall bladder emptying in acromegalic patients given octreotide were considerably greater than those seen in control subjects. However, none of these differences was statistically significant.

\section{octreotide treatment}

The most striking difference in the gall bladder volume-time profile between acromegalic patients treated long term with octreotide and those given a single injection of the somatostatin analogue was in the fasting volume - the mean value of $50.3(8.4) \mathrm{ml}$ after long term treatment being $25 \%$ greater than that seen in the saline $(40.2(4.9) \mathrm{ml})$, and in the single dose octreotide $(40.2(6.5) \mathrm{ml})$ studies, although this difference was not statistically significant.

The gall bladder emptying in response to the fat-rich test meal was again impaired, with significant reductions in the delta volume, ejection fraction, and rate of gall bladder emptying, when compared with the corresponding measurements in untreated patients. The reduction in quantity of bile expelled after the meal stimulus (delta volume and ejection fraction), and the rate of gall bladder emptying, were less noticeable during long term octreotide treatment than after a single injection - suggesting possible tachyphylaxis or the development of tolerance to long term octreotide. 

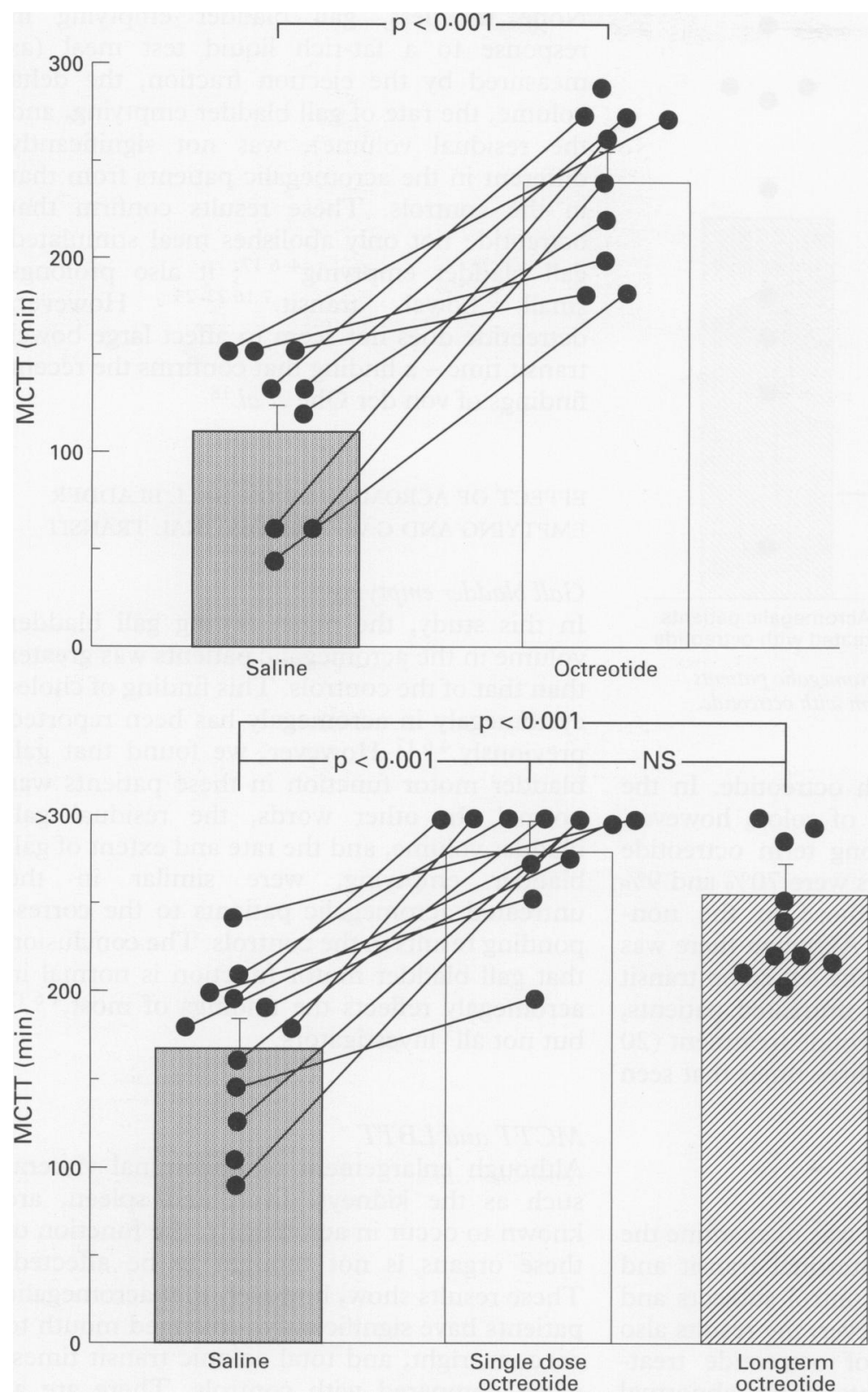

Figure 3: Mouth to caecum transit time (MCTT), measured by the breath hydrogen technique, in control subjects (upper panel) and acromegalic patients (lower panel) given a subcutaneous injection of either saline or octreotide $(50 \mu \mathrm{g}), 30$ minutes before a fat-rich, lactulose containing liquid meal (see text). The data for acromegalic patients during long term octreotide treatment are also given (see legend to Fig 1).

As the presence of gall bladder stones is, of itself, associated with changes in meal stimulated gall bladder emptying, in theory inclusion of the results in the two patients who developed stones during long term octreotide treatment, could have influenced the outcome. The pattern of results was virtually identical, however, whether or not the data in those two subjects were included.

\section{MCTT}

Figure 3 shows the results for MCTT in the paired studies (saline $v$ octreotide) of control subjects (upper panel) and acromegalic patients (lower panel). The lower panel also shows the results for MCTT in acromegalic patients treated long term with octreotide.

After the placebo (saline) injection, the mean MCTT in the acromegalic patients was $52 \%$ longer $(p<0.01)$ than that in the control subjects. In other words, acromegaly in itself affected gastric and small bowel transit, as measured by the MCTT, as well as gall bladder emptying.

In both the control subjects and the acromegalic patients, octreotide given 30 minutes before the test meal considerably prolonged the MCTT. Thus in the control subjects, the MCTT increased from 112 (15) minutes after saline to 237 (13) minutes after octreotide $(\mathrm{p}<0.001)$. In the acromegalic patients, the corresponding increase was from 170 (13) minutes to 282 (11) minutes $(p<0.001)$. In fact after octreotide, seven of 11 acromegalic patients studied had not shown a rise in breath hydrogen by 300 minutes after the meal when the observations were abandoned.

In acromegalic patients treated long term with octreotide, the MCTT was still significantly $(p<0.001)$ prolonged compared with that in the non-octreotide treated patients given saline (Fig 3). After long term octreotide, however, the MCTT of 247 (10) minutes was significantly $(p<0.05)$ shorter than that in the acromegalic patients given a single dose of octreotide (282 (11) minutes) - again suggesting possible tachyphylaxis.

LBTT

Figure 4 shows the results for LBTT in the control subjects and the acromegalic patients untreated with octreotide, and treated long term ( $>$ three months) with octreotide. Figure 5 gives the corresponding data for segmental colonic transit times.

In the control subjects, the mean LBTT was 18 (2) hours (range 2-36). In the nonoctreotide treated acromegalic patients, the mean value of 40 (6) hours was more than twice that seen in the controls and despite a considerable scatter of results (range 2-64 hours), the mean value was significantly greater than that in controls $(\mathrm{p}<0.005)$.

In the acromegalic patients taking long term octreotide, the mean LBTT of 47 (6) hours was $161 \%$ greater than that in controls $(p<0.005)$. The LBTT in both the untreated and the treated acromegalics was similar suggesting that octreotide has no consistent effect on colonic transit. However, paired studies in larger numbers of patients would be needed to prove or disprove this conclusion.

Analysis of segmental colonic transit (Fig 5) showed that the mean time for the right colon in the untreated acromegalic patients (18 (3) hours), was three times longer than that in the control subjects (6 (1) hours, $p<0.005)$. A similar pattern of results was seen in the left (12 (3) $v 6$ (1) hours) and the sigmoid (10 (3) $v 6$ (1) hours) segments of colon, although these differences were not statistically significant.

There were no significant differences in segmental colonic transit times between the acromegalic patients taking long term octreotide, and those untreated with octreotide. Indeed, the pattern of results was quite variable. Thus, in the right colon, transit was shorter during long term octreotide treatment than in 


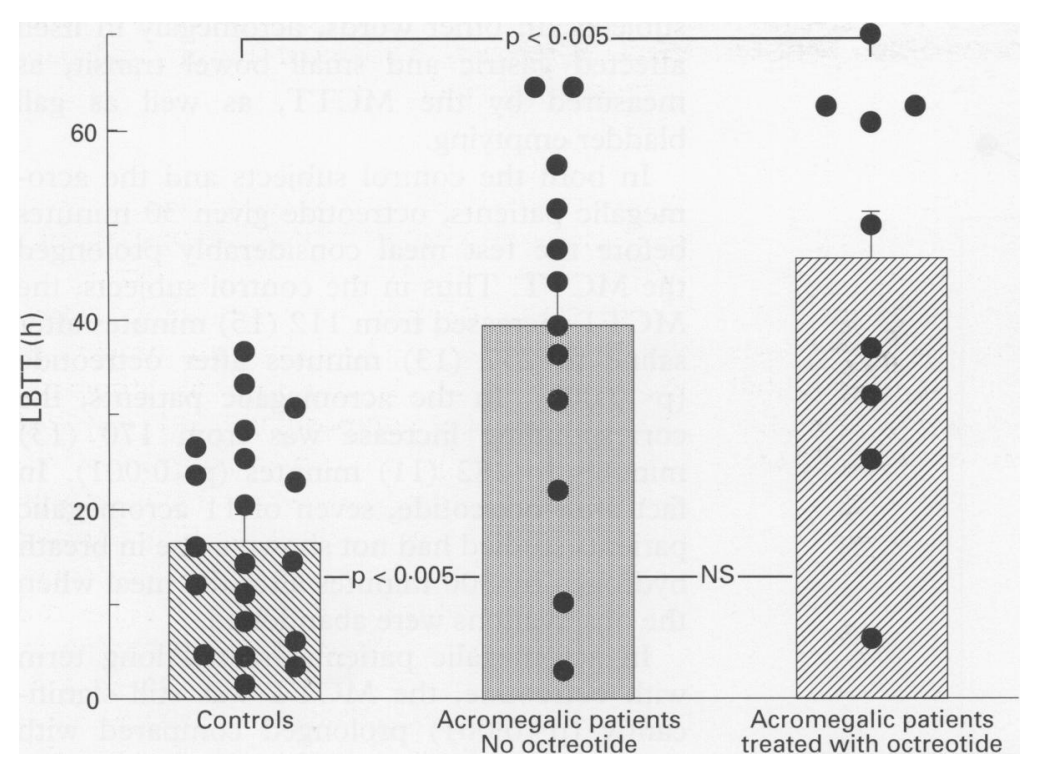

Figure 4: Large bowel transit times (LBTT) in control subjects, acromegalic patients untreated with octreotide, and acromegalic patients treated long term with octreotide.

the patients untreated with octreotide. In the left and sigmoid segments of colon, however, the mean values in the long term octreotide treated acromegalic patients were $70 \%$ and $9 \%$ higher respectively than those in the nonoctreotide treated patients. Although there was no significant difference in the left colon transit times between treated and untreated patients, the mean value during octreotide treatment (20 (5) hours) was more than three times that seen in controls $(6(1) ; p<0 \cdot 05)$.

\section{Discussion}

The main aim of this paper was to examine the effects of octreotide on intestinal transit and gall bladder emptying in control subjects and acromegalic patients. However, the results also show that, independent of octreotide treatment, acromegalic patients have abnormal intestinal transit and a greater than normal fasting gall bladder volume (cholecystomegaly).

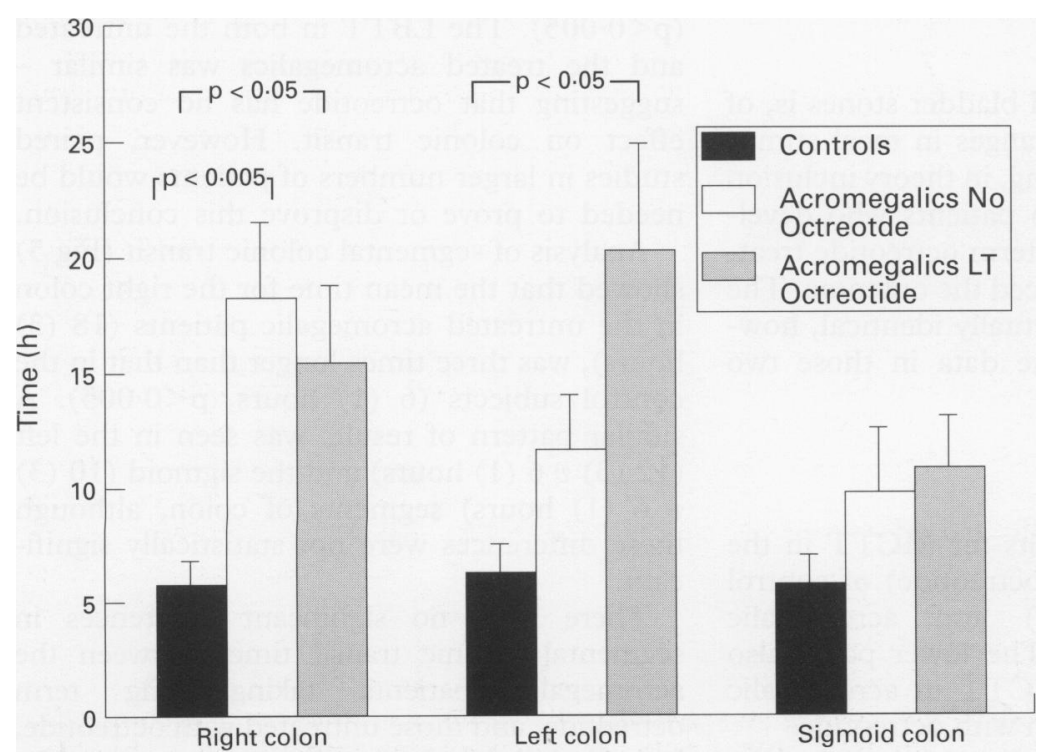

Figure 5: Segmental transit times for the right, left, and sigmoid colons in control subjects, acromegalic patients untreated with octreotide, and acromegalic patients treated long term with octreotide.
None the less, gall bladder emptying in response to a fat-rich liquid test meal (as measured by the ejection fraction, the delta volume, the rate of gall bladder emptying, and the residual volume), was not significantly different in the acromegalic patients from that in the controls. These results confirm that octreotide not only abolishes meal stimulated gall bladder emptying ${ }^{4-617}$; it also prolongs small bowel transit. ${ }^{7} 16$ 23-25 However, octreotide does not seem to affect large bowel transit time - a finding that confirms the recent findings of von der Ohe et al. ${ }^{18}$

\section{EFFECT OF ACROMEGALY ON GALL BLADDER} EMPTYING AND GASTROINTESTINAL TRANSIT

\section{Gall bladder emptying}

In this study, the mean fasting gall bladder volume in the acromegalic patients was greater than that of the controls. This finding of cholecystomegaly in acromegaly has been reported previously. ${ }^{4617}$ However, we found that gall bladder motor function in these patients was normal. In other words, the residual gall bladder volume, and the rate and extent of gall bladder emptying, were similar in the untreated acromegalic patients to the corresponding results in the controls. The conclusion that gall bladder motor function is normal in acromegaly reflects the findings of most, ${ }^{4617}$ but not all ${ }^{5}$ investigators.

\section{MCTT and LBTT}

Although enlargement of abdominal viscera, such as the kidneys, liver, and spleen, are known to occur in acromegaly, the function of these organs is not thought to be affected. These results show, however, that acromegalic patients have significantly prolonged mouth to caecum, right, and total colonic transit times, when compared with controls. There are at least two possible ways by which acromegaly could affect intestinal transit. Firstly, an increase in the physical length of the bowel could prolong both the MCTT and the LBTT, without changing segmental transit rates. Secondly, the excess circulating growth hormone and IGF-1 concentrations seen in acromegaly, could affect local neuro-hormonal mechanisms controlling gut motility. ${ }^{26} 27$ To date, neither of these hypothetical mechanisms has been tested adequately.

The two groups studied, namely control subjects and acromegalic patients, were matched for sex but not for age. Women have longer MCTTs in the luteal phase of the menstrual cycle, than in the follicular phase. ${ }^{28} \mathrm{We}$ did not control for this but as the proportion of women was comparable in the two groups, the prolongation of MCTT seen in the acromegalic patients is unlikely to result from differences in the ratio of men:women. Moreover, although the control and patient groups were not matched for age, there is no evidence that either small29-32 or large 22 bowel transit changes in older people. 
EFFECT OF OCTREOTIDE ON GALL BLADDER EMPTYING AND GASTROINTESTINAL TRANSIT

\section{Gall bladder emptying}

These findings confirm the results of previous studies showing that a single dose of octreotide impairs gall bladder emptying both in control subjects ${ }^{7334}$ and in acromegalic patients. ${ }^{46}$ Other investigators have shown that long term octreotide treatment increases both the fasting and the residual postprandial gall bladder volumes, 461735 as well as reducing the speed and extent of gall bladder emptying. ${ }^{4-6} 173637$

The mechanism for the increased fasting gall bladder volume after octreotide administration is unknown but may be caused by: (a) reduced gall bladder muscle tone, (b) the absence of interdigestive gall bladder emptying, or (c) increased tone in the sphincter of Oddi. ${ }^{38}$

Cholecystokinin mediates postprandial gall bladder contraction via cholinergic receptors in the myenteric plexus of the gall bladder wall. ${ }^{39}$ Therefore, the influence of the somatostatin analogue on gall bladder emptying is probably caused by the combined effects of octreotide on meal stimulated cholecystokinin release from the duodenum ${ }^{467}$ and a direct action of octreotide on acetylcholine release from the myenteric plexus. ${ }^{40}$

\section{MCTT and LBTT}

Although both a single dose of, and long term treatment with, octreotide, prolonged the MCTT, the analogue had no consistent effect on large bowel transit. Therefore, the influence of octreotide on intestinal motility seems to be site dependent. Similar site specific and dose dependent effects have been reported in animals. Thus, in dogs with an ileus induced by celiotomy and intestinal abrasion, low dose octreotide increased gastric emptying and reduced both small bowel and colonic transit. At a higher dose, however, octreotide slowed gastric emptying while still stimulating small and large bowel transit. ${ }^{41}$

The effect of octreotide on intestinal motility is different when patients are fasting, from that seen after food. Octreotide increases the frequency of intestinal migrating motor complexes. ${ }^{42}$ Richards and colleagues ${ }^{43}$ found that in six patients with the dumping syndrome, octreotide increased interdigestive motility. Moreover, octreotide decreased the duration of the postprandial 'fed' motility pattern from a mean of 141 minutes after placebo, to 29 minutes after octreotide. Therefore, octreotide seems to have a stimulatory effect on intestinal transit in the interdigestive state, but an inhibitory one after a meal.

Evidence for a direct effect of octreotide on intestinal somatostatin receptors comes from the finding that an intra-arterial infusion of native somatostatin into canine intestinal segments, induces phase III migrating motor complexes. ${ }^{44}$ However, octreotide may also affect motility indirectly by inhibiting the release of intestinal peptides that influence gastrointestinal motor function - such as cholecystokinin, motilin, peptide tyrosine tyrosine (peptide YY), neurotensin, and pancreatic polypeptide. ${ }^{716}$

ROLE OF INTESTINAL TRANSIT AND GALL BLADDER EMPTYING IN THE PATHOGENESIS OF OCTREOTIDE INDUCED GALL STONE DISEASE

There is a number of possible mechanisms by which octreotide could induce an increase in the \% biliary DCA, and thus in lithogenic changes in bile composition and physical chemistry. Firstly, it could prolong intestinal transit. The resultant increase in the 'residence time' of bile acids in the intestine would favour more bacterial conversion of cholic to deoxycholic acid. Secondly, it could increase the absolute number of micro-organisms either in the colon or, by inducing bacterial overgrowth, in the small intestine. Thirdly, it could increase in the ratio of anaerobic:aerobic bacteria in the bowel - both of which changes could increase the total amount of bacterial $7 \alpha$ dehydroxylase activity in the intestine. Fourthly, it could induce bacterial $7 \alpha$ dehydroxylase enzyme specific activity, while leaving the number and type of intestinal micro-organisms unchanged. Finally, the impaired gall bladder emptying induced by octreotide could result in the sequestration of much of the bile acid pool within the gall bladder, with more rapid than normal enterohepatic cycling of the remaining pool - analogous to the changes described after cholecystectomy by some, ${ }^{14} 45-47$ but not all ${ }^{15} 4849$ investigators.

Despite the many theoretical explanations for the increase in the \% DCA conjugates seen in bile during octreotide treatment, the results of this study provide strong indirect evidence that a major mechanism for the changed biliary bile acid composition, is prolongation of intestinal transit. Our findings support those of previous studies showing that both native somatostatin, ${ }^{50-53}$ and its analogue octreotide, ${ }^{71623-25}$ prolong the MCTT in control subjects. Furthermore, we have shown that a single dose of octreotide prolongs the MCTT in acromegalic patients. However, the conversion of cholic acid to deoxycholic acid occurs predominantly in the caecum and ascending colon - rather than in the small bowel. ${ }^{54-56}$ In our acromegalic patients treated long term with octreotide, LBTT was not significantly greater than that in acromegalic patients untreated with octreotide. However, given, the small numbers of patients studied and the wide scatter of results, this apparent lack of effect could be a type II statistical error. Alternatively, the conversion of primary to secondary bile acids could occur in the small bowel, rather than in the large bowel, of the octreotide treated acromegalic patients - if, as postulated above, there were bacterial overgrowth after prolongation of small bowel transit.

In conclusion, the studies described in this paper have shown that in acromegalic patients, octreotide impairs gall bladder emptying and prolongs intestinal transit. These findings provide further strong, but still 
indirect, evidence that octreotide induced changes in intestinal transit may lead to an increased proportion of biliary DCA. In turn, the rise in \% DCA induces a complex series of changes in bile composition and physical chemistry, which, together with the impaired gall bladder emptying, favour cholesterol gall stone formation.

This work was supported, in part, by grants from the Special Trustees of Guy's Hospital and Sandoz Pharma Ltd. These data were presented in part at the meeting of the British Society of Gastroenterology (Gut 1994; 35 (suppl 2): S57), the joint of Gastroenterology (Gut 1994; 35 (suppl 2): S57), the joint meeting of the British Endocrine Societies ( $P$ Endocrinol 1994; 140 (S): 60), the 3rd United European Gastroenterology Week
(Gut 1994; 35 (suppl 4): A40 and A109), and XIII International (Gut 1994; 35 (suppl 4): A40 and A109), and XIII International eds. Bile acids in gastroenterology: basic and clinical advances. Falk symposium No 80. Dordrecht: Kluwer Academic Press, 1995 319-32.

1 Ho KY, Weissberger AJ, Marbach P, Lazarus L. Therapeutic efficacy of the somatostatin analog SMS 201 995 (octreotide) in acromegaly. Ann Intern Med 1990; 112: $173-81$.

2 Dowling RH, Hussaini SH, Murphy GM, Besser GM, Wass JAH. Gallstones during octreotide therapy. Metabolism 1992; 41 (S2): 22-33.

3 Dowling RH, Gleeson D, Ruppin DC, Murphy GM Gallstone recurrence and post-dissolution management. In: Paumgartner G, Stiehl A, Gerok W, eds. Enterohepatic circulation of bile acids and sterol metabolism. Lancaster, England: MTP Press, 1984: 361-70.

4 van Liessum PA, Hopman WP, Pieters GF, Jansen JB Smals AG, Rosenbusch G, et al. Post prandial gallbladder motility during long term treatment with the long-acting somatostatin analogue SMS 201-955 in acromegaly. f Clin Endocrinol Metab 1989; 69: 557-62.

5 Catnach SM, Anderson JV, Fairclough PD, Trembath RC Wilson PAJ, Parker E, et al. The effect of octreotide on gallstone prevalence and gallbladder motility in acromegaly. Gut 1993; 34: 270-3.

6 Stolk MFJ, van Erpecum KJ, Koppeschaar HPF, de Bruin WI, Jansen JBM, Lamers CBWH, et al. Postprandial gallbladder motility and hormone release during intermittent and continuous subcutaneous octreotide treatment in acromegaly. Gut 1993; 34: 808-13.

7 Lembcke B, Creutzfeldt S, Schlesser R, Ebert R, Shaw C, Koop I. Effect of somatostatin analogue (SMS 201-995) on gastrointestinal, pancreatic and biliary function and hormone release in normal man. Digestion 1987; 36: 108-24.
Creutzfeldt W, Lembcke B, Follsh UR, Schleser S, Koop I. The effect of somatostatin analogue (SMS 201-995, Sandostatin) on pancreatic secretions in humans. $A m$ fMed 1987; 82: 49-54.

9 Hussaini SH, Murphy GM, Kennedy C, Besser GM, Wass JAH, Dowling RH. The role of bile composition and physical chemistry in the pathogenesis of octreotideassociated

10 Thornton JR, Heaton KW. Do colonic bacteria contribute to cholesterol gall stone formation? Effects of lactulose on bile. $B M F$ 1981; 282: 1018-20.

11 Thornton JR, Emmett PM, Heaton KW. Diet and gallstones: effects of refined and unrefined carbohydrate diets on bile cholesterol saturation and bile acid metabolism. Gut 1983; 25: 269-74.

12 Marcus SN, Heaton KW. Intestinal transit, deoxycholic acid and the cholesterol saturation of bile: three interrelated factors. Gut 1986; 27: 550-8.

13 Carey MC, Cahalane MJ. Whither biliary sludge. Gastroenterology 1988; 95: 508-23.

14 Roda E, Aldini R, Mazella G, Roda A, Sama C, Festi D, et al. Enterohepatic circulation of bile acids after cholecystectomy. Gut 1978; 19: 640-9.

15 Kullak-Ublick GA, Paumgartner G, Berr F. Long-term effects of cholecystectomy on bile acid metabolism. Hepatology 1995; 21: 41-5.

16 Fuessl HS, Carolan G, Williams G, Bloom SR. Effect of a long-acting somatostatin analogue (SMS 201-995) on postprandial gastric emptying of $99 \mathrm{mTc}$-tin colloid and mouth-to-caecum transit time in man. Digestion 1987; 36: 101-7.

17 Hopman WP, van Liessum PA, Pieters GF, Jansen JB, Lamers CB, Smals AG, et al. Postprandial gallbladder motility and plasma cholecystokinin at regular time intervals after injection of octreotide in acromegalics on intervals after injection of octreotide in acromegalics
long-term treatment. Dig Dis Sci 1992; 37: 1685-90.

18 von der Ohe MR, Camilleri M, Thomforde GM, Klee GG. Differential regional effects of octreotide on human gasDifferential regional effects of octreotide on huma
trointestinal motor function. Gut 1995; 36: 743-8.

19 Dodds WJ, Groh WJ, Darweesh RMA, Lawson TL, Kishk SMA, Kern MK. Sonographic measurement of gallbladder volume. Am f Roentgenol 1985; 145: 1009-11.

20 Bond JH, Levitt MD. Investigation of small bowel transit time in man utilizing pulmonary hydrogen measurements. f Lab Clin Med 1974; 85: 546-56.

21 Howard PJ, Lazarus C, Maisey MN, Dowling RH. Interpretation of postprandial breath hydrogen excretion in relation to small bowel transit and ileocecal flow patterns of a radiolabeled solid meal in man. $f$ Gastrointest Motil 1990; 2: 194-201.

22 Metcalf AM, Phillips SF, Zinsmeister AR, MacCarty RL, Beart RW, Wolff BG. Simplified assessment of segmental colonic transit. Gastroenterology 1987; 92: 40-7.

23 Deuno MI, Bai JC, Sanangelo WC, Krejs GJ. The effect of somatostatin analogue on water and electrolyte transport and transit time in human small bowel. Dig Dis Sci 1987; 32: $1092-6$.

24 Møller N, Petrany G, Cassidy D, Sheldon WJ, Johnston DG, Laker MF. Effects of somatostatin analogue SMS 201-995 (sandostatin) on mouth-to-caecum transit time and absorption of fat and carbohydrates in normal man. Clin Sci 1988; 750: 345-50.

25 O'Donnell LJD, Watson AJM, Cameron D, Farthing MJG. Effect of octreotide on mouth-to-caecum transit time in healthy subjects and in the irritable bowel syndrome. healthy subjects and in the irritable bowe
Aliment Pharmacol Therap 1990; 4: 177-82.

26 Nicholl CG, Polak JM, Bloom SR. The hormonal regulation of food intake, digestion, and absorption. Nutrition 1985; 5: 213-39.

27 Torsoli A, Severi C. The neuroendocrine control of gastrointestinal motor activity. I Physiol 1993; 87: 367-74.

28 Wald A, van Thiel DH, Hoechstetter L, Gavaler JS, Egler KM, Verm R, et al. Gastrointestinal transit: the effect of the menstrual cycle. Gastroenterology 1981; 80: 1497-500.

the menstrual cycle. Gastroenterology 1981; 80: 1497-500.
29 Fich A, Camilleri M, Phillips SF. Effect of age on human gastric and small bowel motility. F Clin Gastroenterol 1989; 11: 416-20.

30 Kupfer RM, Heppell M, Haggith JW, Bateman DN. Gastric emptying and small bowel transit in the elderly. $\mathcal{F} \mathrm{Am}$ Geriatr Soc 1985; 33: 340-3.

31 Wegener MG, Scharffstein J, Lüth J, Rickels R, Ricken D The effect of ageing on the gastrointestinal transit of a lactulose supplemental solid-liquid meal in humans. Digestion 1988; 39: 40-6.

32 Piccione PR, Holt PR, Culpepper-Morgan JA, Paris $\mathrm{P}$ O'Bryan L, Ferdinands L. Intestinal dysmotility syndromes in the elderly: measurements of oro-cecal transit dromes in the elderly: measurements of oro-

33 Mitsukawa T, Takemura J, Nishizono F, Nakatsuru K, Ohgo S, Matsukura S. Effects of atropine, proglumide, and somatostatin analogue (SMS 201-995) on bombesininduced gallbladder contraction and CCK secretion in humans. Am $\mathcal{F}$ Gastroenterol 1989; 84: 1371-4.

34 Zhu XF, Shi YF, Qin-Dai, Zhang JX, Harris AG. Effect of small doses of somatostatin analog, octreotide, on gallbladder contractility in normal Chinese adults. Dig Dis Sci 1992; 37: 105-8.

35 Bigg-Wither GW, Ho KYY, Grunstein RR, Sullivan CE, Doust BD. Effect of long term octreotide on gall stone formation and gallbladder function. $B M \mathcal{F}$ 1992; 304: formation

36 Ewins DL, Javaid A, Coskeran PB, Shah S, Butler J, Deprez $\mathrm{PH}$, et al. Assessment of gall bladder dynamics, cholecystokinin release and the development of gallstones during octreotide therapy for acromegaly. $Q \mathcal{F}$ Med 1992; 83: 295-306.

37 Rhodes M, James RA, Bird M, Clayton B, Kendall-Taylor $P$, Lennard TW. Gallbladder function in acromegalic patients taking long-term octreotide: evidence of rebound hypermotility on cessation of treatment. Scand $f$ Gypermotility on cessation

Gastroenterol 1992; 27: 115-8.
38 Binmoeller KF, Dumas R, Harris AG, Delmont JP. Effect of somatostatin analogue octreotide on human sphincter of oddi. Dig Dis Sci 1992; 37: 773-7.

39 Takahashi I, Suzuki T, Aizawa I, Itoh Z. Comparison of gallbladder contractions induced by motilin and cholecystokinin in dogs. Gastroenterology 1982; 82: 419-24.

40 Guilliemin R. Somatostatin inhibits the release of acetylcholine induced electrically in the myenteric plexus. Endocrinology 1976; 99: 1653-4.

41 Cullen JJ, Eagon JC, Dozois EJ, Kelly KA. Treatment of acute postoperative ileus with octreotide. Am $\mathcal{F}$ Surg 1993; 165: 113-9.

42 Soudah HC, Hasler WL, Owyang C. Effect of octreotide on intestinal motility and bacterial overgrowth in sclerointestinal motility and bacterial overgro

43 Richards WO, Geer R, O'Dorisio TM, Robarts T, Parish $\mathrm{KL}$, Rice D, et al. Octreotide acetate induces fasting small bowel motility in patients with the dumping syndrome. f Surg Res 1990; 49: 483-7.

44 Hostein J, Janssens J, Vantrappen G, Peeters TL Vandeweerd M, Leman G. Somatostatin induces ectopic activity fronts of the migrating motor complex via a local intestinal mechanism. Gastroenterology 1984; 87: 1004-8.

45 Pomare EW, Heaton KW. The effect of cholecystectomy on bile acid metabolism. Gut 1973; 14: 753-62.

46 Shaffer E, Small DM. Biliary lipid secretion in cholesterol gallstone disease. The effect of cholecystectomy and gallstone disease. The effect of chol
obesity. $\mathcal{F}$ Clin Invest 1977; 59: 828-40.

47 Hepner GW, Hofmann AF, Malagelada JR, Szezepanik PA Klien PD. Increased bacterial degradation of bile acids in Klien PD. Increased bacterial degradation of bile acids in
cholecystectomized patients. Gastroenterology 1974; 66: cholecys

48 van der Linden W, Katzenstein B, Nakayama F. The possible carcinonogenic effect of cholecystectomy: no post-operative increase in the proportion of secondary bile acids. Cancer 1983; 52: 1265-8.

49 Berr F, Stellaard F, Pratschke E, Paumgartner G. Effects of cholecystectomy on the kinetics of primary and secondary bile acids. F Clin Invest 1989; 83: 1541-50.

50 Efendic S, Mattsson O. Effect of somatostatin on intestinal motility. Acta Radiol 1978; 19: 348-52. 
51 Johansson C, Efendic S, Wisen O, Uvnas-Wallensten K, Luft R. Effects of short time somatostatin infusion on gastric and intestinal propulsion in humans. Scand $\mathcal{f}$ Gastroenterol 1978; 13: 481-3.

52 Konturek SJ. Somatostatin and gastrointestinal secretion and motility. Adv Exp Med Biol 1978; 106: 227-34.

53 Johansson C, Efendic S, Wisen O, Uvnas-Wallensten $\mathrm{K}$. Effects of somatostatin on gastrointestinal propagation Effects of somatostatin on gastrointestinal propagation and absorption of oral glucose in man. Digestion 1981; 22:
54 MacDonald IA, Bokkenheuser VD, Winter J, McLernon $\mathrm{AM}$, Mosbach EH. Degradation of steroids in the human gut. F Lipid Res 1983; 24: 675-700.

55 Morris JS, Low-Beer TS, Heaton KW. Bile salt metabolism in the colon. Scand 7 Gastroenterol 1973; 8: 425-31.

56 Yahiro K, Setoguchi T, Katsuki T. Effect of cecum and appendix on 7 alpha-dehydroxylation and 7 beta-epimer1980; 21: 215-22. 